\title{
História da obesidade: a filmografia de Georges Méliès
}

\section{RESUMO}

Este artigo objetivou analisar as representações sociais cinematográficas da obesidade e de seus precursores conceituais na filmografia de Georges Méliès. Um total de 198 filmes, produzidos entre 1896 a 1913, foram analisados através da análise discursiva da enunciação, numa perspectiva foucaultiana. Vinte e seis filmes foram considerados relevantes, dos quais extraiu-se 31 trechos considerados significativos. Os enunciados constituídos foram agrupados em seis formações discursivas, com conteúdos que associavam a condição a questões de status socioeconômico, beleza, capacidades físicas e comportamentos. Concluiu-se que o material analisado é uma fonte histórica primária importante para a história da obesidade, indicando que o cinema pode ter sido uma ferramenta de propaganda na divulgação da inversão valorativa que ocorreu no processo histórico de patologização da condição.

PALAVRAS-CHAVE: Obesidade; História. Filmes cinematográficos

\section{Cezar Barbosa Santolin}

Mestre em Educação Física

Universidade Federal de Mato Grosso do Sul (UFMS),

Curso de Educação Física, Corumbá, Brasil cezarsantolin@hotmail.com.br (1) https://orcid.org/0000-0002-4031-6486 


\title{
History of obesity: Georges Méliès's filmography
}

\begin{abstract}
This article aimed to analyze the social cinematographic representations of obesity and its conceptual precursors in the filmography of Georges Méliès. A total of 198 films, produced between 1896 and 1913, were analyzed through the discursive analysis of the enunciation, in a Foucaultian perspective. Twenty-six films were considered relevant, from which 31 excerpts were considered significant. The constituted statements were grouped into six discursive formations, with contents that associated the condition with questions of socioeconomic status, beauty, physical capacities and behaviors. It was concluded that the analyzed material is an important primary historical source for the history of obesity, indicating that cinema may have been a propaganda tool in the dissemination of the valuation inversion that occurred in the historical process of pathologization of the condition.
\end{abstract}

KEYWORDS: Obesity; History; Motion pictures

História de la obesidade: la filmografía de Georges Méliès

\section{RESUMEN}

Este artículo tuvo como objetivo analizar las representaciones cinematográficas sociales de la obesidad y sus precursores conceptuales en la filmografía de Georges Méliès. Un total de 198 películas, producidas entre 1896 y 1913, fueron analizadas a través del análisis discursivo de la enunciación, en una perspectiva foucaultiana. Se consideraron relevantes veintiséis películas, de las cuales 31 extractos se consideraron significativos. Los enunciados constituidos se agruparon en seis formaciones discursivas, con contenidos que asociaban la condición con cuestiones de nivel socioeconómico, belleza, capacidades físicas y comportamientos. Se concluyó que el material analizado es una importante fuente histórica primaria para la historia de la obesidad, lo que indica que el cine pudo haber sido una herramienta propagandística en la difusión de la inversión valorativa que se produjo en el proceso histórico de patologización de la condición.

PALABRAS-CLAVE: Obesidad; Historia. Películas cinematográficas 


\section{INTRODUÇÃO}

$\mathrm{Na}$ história da obesidade, houve um fenômeno sociocultural de inversão dos valores atribuídos à certa característica corporal. Conforme Vigarello (2012) e Santolin (2012), esse processo histórico de problematização do tamanho, composição, aparência e peso corporais teria se iniciado pelo século XVIII, na Europa. Ao fim, restou um discurso mais ou menos patologizante, preponderante de meados do século XX até a atualidade. Ao longo desta patologização, ocorreram certas associações espúrias entre as características corporais e outros aspectos, que nada tinham a ver com a questão, que, anteriormente, era considerada salutar, bela, poderosa, potente e rica (SANTOLIN e RIGO, 2012).

Ainda na virada para o século XX, a inversão valorativa e a patologização estavam restritas ao campo médico, não tendo se popularizado (SANTOLIN e RIGO, 2015). Assim, cogitou-se que o Cinema - inventado no final do século XIX - possa ter sido uma ferramenta midiática de divulgação dos novos valores e das concepções medicalizadas. Neste sentido, hipotetizou-se que a filmografia do francês Georges Méliès (1861-1938) - um dos pioneiros do Cinema - poderia conter peças importantes para montar o quebra-cabeça histórico.

A companhia Star Film, fundada por Méliès em 1902, dominou o mercado cinematográfico até 1906. Apesar da produção artesanal, ao longo de dezoito anos, entre 1896 e 1913, Méliès produziu 533 curtas (IMDb, 2018; LA MAGIE MÉLIÈS, 1997; JULLIER, MARIE e MARIE, 2012). Seus filmes obtiveram muito sucesso na época, mas ao final da vida, devido a problemas de pirataria nos Estados Unidos da América e mudanças nos tipos de filmes desejados pelo público, Méliès teve que vender seu estúdio e terminou relativamente falido. Amargurado, prestes a vender também seu teatro, teria queimado parte de seus filmes (LA MAGIE MÉLIÈS, 1997). Em trabalho de restauração, após longa pesquisa e coleta em todo o mundo, a Cinematèque Française recuperou a filmografia restante, publicando uma coleção, aparentemente definitiva, composta por seis DVDs, com 199 dos 533 curtas produzidos.

Assim, em vista de contribuir para o estudo da história da obesidade, o objetivo da presente pesquisa foi analisar as representações sociais cinematográficas da obesidade e de seus precursores conceituais na filmografia de Georges Méliés. 


\section{MATERIAIS E MÉTODOS}

O presente estudo pode ser classificado como um estudo histórico (STRUNA, 2007), assim como sociológico, por tratar de representações sociais (RS) (MOSCOVICI, 2010). O material empírico analisado consistiu nos filmes presentes na coleção Georges Méliès: the first wizard of Cinema (Georges Méliès: o primeiro mago do cinema, 2010), com exceção do filme Hidroterapia fantástica, que será analisado separadamente por conta da relevância para a temática. A duração do material analisado totalizou 742 minutos - ou cerca de 12,5 h. Apesar da referida coleção restaurada pertencer à Lobster Films, todos os filmes podem ser acessados e assistidos gratuitamente, sem infringir a leis de direitos autorais, já que se encontram em domínio público, através da plataforma de vídeos Youtube.

Para a coleta de dados, realizou-se uma primeira assistência do material, desenvolvendo uma análise superficial da obra como um todo, identificando se a mesma conteria algo relevante para a temática. Tendo considerado o filme relevante, realizou-se uma segunda visualização, na qual

foram descritas com maior grau de detalhamento trechos importantes. Após isso, buscou-se constituir, a partir das descrições e análises, quais enunciados a respeito da obesidade, dos obesos e de seus precursores conceituais estariam presentes nas RS do filme. Cada trecho foi categorizado em um ou mais núcleos centrais (NC) de significado, de acordo com o conteúdo de suas RS. Este procedimento advém da Teoria do Núcleo Central (TNC), de J. C. Abric e C. Flament (PATRIOTA, 2020), derivada da Teoria das Representações Sociais (TRS), de Moscovici (2010).

Quanto aos procedimentos analíticos, os dados foram analisados conforme a metodologia denominada análise discursiva da enunciação, na perspectiva que Michel Foucault apresentou na obra "A Arqueologia do saber" (2008).

Após a constituição dos enunciados, realizou-se uma aproximação enunciativa e do núcleo central (NC) de significado dos conteúdos das RS em vista a produzir formações discursivas, que serão expostas, com as análises e descrições. Optou-se por citar somente o título de cada filme, sem constar nas referências, devido às restrições do número de páginas prevista nas normas deste periódico. A citação aos filmes foi realizada através dos títulos originais, em francês, com tradução livre pelo pesquisador para o português.

Em relação à interpretação e à compreensão das análises empreendidas, adotou-se a teoria hermenêutico-filosófica proposta por Gadamer (2014), cujo modelo teórico equipara, estruturalmente, a compreensão - no qual está inclusa a atividade interpretativa - ao conceito de jogo. 


\section{RESULTADOS E DISCUSSÃO}

Tecnicamente, os filmes de Méliès apresentam um aspecto teatral-circense quanto à composição do cenário, perfil do espetáculo, temas e saudação ao público-espectador na entrada dos atores (olhar-câmera). A câmera é mantida parada - plano fixo e ponto de vista único - enquanto uma das características mais destacadas da linguagem cinematográfica posteriormente, em contraposição ao teatro e a televisão, será a movimentação da câmera (JULLIER, MARIE e MARIE, 2012). Tais características também estão presentes em outros filmes da época, tendo recebido o nome de cinema de atrações (SABADIN, 2000).

Apesar disso, pode-se dizer que já há "filmes" - pois o cinematógrafo já está sendo usado para narrar histórias, com edição, cortes, efeitos especiais, dentre outros itens que podem servir para caracterizar o Cinema. Por isso, há quem diga que Méliès foi o inventor da sétima arte (LA MAGIE MÉLIÈS, 1997; GEORGES MÉLIÈS, 2010).

Muitas obras são peças de "mágica", típicas de circos, mas com o uso de ferramentas cinematográficas, como o corte, a sobreposição, a dupla exposição, etc. Há, também, muitos curtas de terror, com temática mais ou menos religiosa, em que, com frequência, o diabo e demônios representam o mau, enquanto anjos e santos representam o bem. Outro assunto repetido em algum grau são as temáticas históricas, relevantes para os franceses, como Joana D'Arc e o caso Dreyfus . Também há curtas de conto de fadas, como Cinderela.

De toda a coleção, considerou-se que vinte e seis curtas apresentavam conteúdo relevante sobre a obesidade e seus precursores conceituais. Trinta e um trechos considerados mais significativos foram extraídos, totalizando uma duração de cerca de 20 minutos do total de 741 minutos da amostra analisada, o que corresponde a cerca de 3\% - ou seja, relativamente pouco.

Em cerca de $80 \%(n=26)$ desses trechos a tematização foi somente indireta - ou seja, implicada por conta do corpo do ator . Em alguns casos, Méliès utilizou enchimentos, gerando uma aparência corporal artificial para o personagem, que nem sempre foi diretamente tematizada. Possivelmente, o curta que tratou mais diretamente da temática é intitulado Guérison de l'obésité em 5 minutes (A cura da obesidade em 5 minutos, 1910), mas, infelizmente, este filme se perdeu, tendo sido queimado pelo seu próprio criador (LA MAGIE MÉLIÈS, 1997).

Quando se analisou temporalmente a série, não se observou uma tendência em relação ao tipo de tematização presente nas RS - ou seja, não se percebeu aumento ou diminuição na tematização direta. 
Quanto aos enunciados sobre a obesidade, há inconsistência discursiva - ou seja, os enunciados não mantêm um mesmo NC em todas as obras. Por exemplo, há ocasiões em que personagens poderosos são representados por atores gordos e outras por atores magros. Apesar disso, houve recorrências. Julgou-se desnecessária a quantificação da frequência de ocorrência de padrões enunciativos nas representações, pois a raridade não é um problema na perspectiva metodológica de análise discursiva da enunciação foucaultiana.

De fato, cada filme é um caso único e assim deveria ser considerado, procedendo posteriormente uma aproximação, conforme o conteúdo dos enunciados constituídos, para constituir formações discursivas distintas. Aqui, entretanto, optou-se por analisar centenas de curtas, como análise de casos múltiplos, e apresentá-los partindo do pressuposto que a filmografia de um cineasta haveria de ter uniformidade enunciativa nas representações sociais. Este princípio, entretanto, se mostrou relativamente equivocado. Logo, as formações discursivas apresentadas podem ser, até mesmo, antagônicas umas em relação às outras, assim como podem conter enunciados discrepantes dentro da mesma formação discursiva.

Nada impede - e, na verdade, comumente acontece - que coexistam enunciados e formações discursivas opostas num mesmo período e local. Isso não aconteceu somente no período aqui analisado ou na obra de Méliès - pois ainda hoje há rincões socioculturais com sistemas de valores próprios e bastante diversificados em torno da questão da gordura corporal (POULAIN, 2014).

Tanto por serem, em média, extremamente curtos e sem som, os filmes de Méliès padecem ainda mais da primazia que o Cinema dá, conforme Guimarães (2016), ao movimento, ao acontecimento e às ações. Os gestos e a postura corporal substituem a linguagem verbal, dada a ausência de áudio, tornando os discursos mímicos, exagerados para garantir o melhor entendimento do público da mensagem que se deseja transmitir. Mesmo o áudio existente em seus curtas são meras peças musicais de piano, guardando pouca ou nenhuma concordância em relação às representações realizadas.

Essas características limitam as possibilidades de representações da obesidade e de seus precursores conceituais na obra de Méliès à uma questão quase que exclusivamente imagética, não verbal, focada no corpo dos atores, em gestos específicos que remetam ao corpo ou em ações que signifiquem algo relacionado ao corpo no contexto em que estão inseridas. Não há, por exemplo, a possibilidade de diálogos com enunciados sutis nas entrelinhas, de reforço ou de contraposição entre o verbal e o corporal.

Não é, entretanto, a mera existência de um ator ou personagem corpulento num filme que torna sua aparição significativa, prenhe de um discurso enunciativo sobre a corpulência ou a gordura corporal excessiva. Às vezes, a ausência também pode significar - como, por exemplo, a 
não atuação em certos papeis - e ainda que não se comente exaustivamente sobre todos os silenciamentos possíveis, dever-se-ia considerá-los.

Desse modo, identificou-se e constituiu-se, após aproximações temáticas, um total de seis formações discursivas distintas, cujas RS discursavam sobre NC de significância semelhantes.

\section{Les gros}

Uma das formações discursivas que pode ser identificada mais facilmente na coleção é composta por uma subsérie de catorze curtas, em que personagens que ocupam posições de autoridade e poder - os grandes (em francês, les gros) da sociedade, nos dois sentidos do termo foram representados por atores corpulentos ou gordos. Comumente, os demais personagens desses curtas, que não são figuras de autoridade, foram representados por atores magros.

Como ressaltado por Guimarães (2016), o corpo do ator também integra a representação cinematográfica. Neste sentido, a escolha de um ator corpulento e gordo para representar um papel não é insignificante e, provavelmente, não é casual, pois como destaca Bahiana (2012, s.p.) “(...) nada do que está na tela, em momento algum, é gratuito ou por acaso; tudo o que está na tela, a qualquer momento, tem uma razão de ser. Ou pelo menos deve ter - erros acontecem, acidentes também".

Juízes, monarcas, nobres, príncipes, princesas, padres, patrões, poderosos e ricos ostentam barrigas grandes - naturais ou artificiais - representando algo que poderia ou não ser ainda uma realidade na França que Méliès via, na virada do Século XIX para o XX.

Essa concepção de hierarquização socioeconômica através do tamanho da barriga pode ser entendida como uma espécie de remanescente de séculos anteriores - XVIII e XIX. Como conta Baecque (1989), houve, inclusive, um movimento francês anti nobreza que se auto intitulou le peuple contre les gros (o povo contra os "grandes" - ou os gordos) - que se utilizava politicamente da diferença corporal entre certos grupos socioeconômicos para incitar um movimento revolucionário, rebelde ou de resistência.

Ainda que esses curtas não sejam inteiramente de comédia - pois há muitos de ilusionismo, assim como de terror, drama, históricos, etc. - há muitos filmes que almejam desencadear o riso. Não há nessas representações, entretanto, unanimidade favorável ou resistente à essa autoridade da barriga - ou seja, há uma certa ambiguidade irreverente em relação ao respeito pelas figuras de poder e autoridade, geralmente representadas corpulentas e barrigudas. Se por um lado Méliès as representa respeitosamente, replicando nos filmes o respeito que tais categorias socioeconômicas 
gozavam na sociedade, por outro lado, o cineasta introduz pequenas situações de ridicularização, camufladas pela comicidade. Aparenta, portanto, desejar expressar irreverência, contestação e subversividade, mas conter-se - talvez por medo, já que tal atitude poderia significar no mundo real, em relação à sua posição social em Paris, e a aceitação de seus filmes como entretenimento permitido para as massas.

Em outras palavras, não se faz rir de representações de características que pertençam à elite. Geralmente, faz-se comédia às custas de alguém ou de alguns, que são pegos como bodes expiatórios cômicos. Ao comediante é permitido certa irreverência - e isso será, aparentemente, cada vez mais permitido e incentivado ao longo do Século XX - mas desde que seja com alvos menos destacados do corpo social. Se não se pode dizer a verdade, que "o rei está nu", muito menos rir e fazer rir da nudez de seu corpo. Rir-se do rei, de seu corpo, é, portanto, um ato arriscado (FOUCAULT, 2011).

Ressignificar a corpulência, a gordura e a barriga - símbolos da opulência invejada pelos súditos - tal como a representação caricaturada do rei momo nas festas populares carnavalescas - é um ato de confrontação valorativa no campo sociocultural - e, indiretamente, socioeconômico (QUELLIER, 2011). Rebeldia, sim, mas uma rebeldia progressivamente percebida como inofensiva e que será, cada vez mais, permitida pelos governantes.

Eventualmente, Méliès ridiculariza em suas representações a figura dos "grandes" e de suas corpulências, mas o faz com cautela, quase a lhes pedir autorização, por medo de possíveis consequências. O riso parece uma vingança, como uma facada dos ressentidos e rancorosos. Mas uma "vingança", relativamente inofensiva, inócua em suas pretensões revolucionárias. Dramas vividos nas tramas das disputas sociais pelo poder, em que a aparência dos corpulentos, indiretamente e irremediavelmente, se tornará um alvo fácil.

Posteriormente, já em meados do Século XX, quando a elite emagrecer (POULAIN, 2014), tornar-se-á bem menos arriscado troçar da corpulência excessiva e muitos comediantes o farão, posando de irreverentes, mas não o sendo de verdade. Por enquanto, no começo do Século XX, no tempo de Méliès, ainda é arriscado popularizar essa inversão valorativa.

Um outro ponto relevante é que a representação desses "grandes" contemplava, recorrentemente, outros atributos atrelados - principalmente, um comportamento voluntarioso, dominante, irritadiço, agressivo e - por vezes - violento. Tais associações coadunam-se à uma concepção Antiga e Medieval típica, prévia à inversão valorativa, em que era atribuída uma suposta irascibilidade como característica dos sujeitos considerados corpulentos, tidos como "sanguíneos" ou "pletóricos" dentro da teoria dos quatro humores na medicina (SANTOLIN, 2012; SANTOLIN; RIGO, 2012). 
Deve-se destacar, entretanto, que em muitas dessas representações a personagem da autoridade corpulenta é totalmente secundária na narrativa - ou, ao menos, seu corpo é. Apesar disto, vai produzindo e reproduzindo, ainda que sutilmente, uma enunciação que torna a corpulência uma questão socioeconômica e de poder. Como se pode perceber na publicidade, o impacto ideológico pode ser ainda mais efetivo se as mensagens forem discretas, secundárias, silenciosas, quase inconscientes.

Em Joana D'arc (Joana D'Arc, 1900), somente um padre e o rei são representados por atores corpulentos-gordos, enquanto os demais são magros. Em Les cartes vivantes (As cartas vivas, 1905), o ator que representa o rei também é corpulento e barrigudo. Em Barba azul (Barba azul, 1901), um juiz é representado por um ator gordo. Igualmente, os juízes do caso Dreyfus, em L'affaire Dreyfus, bagarre entre journalistes (O caso Dreyfus, uma briga entre jornalistas, 1899), também são representados por atores corpulentos, reforçando a ideia de que algumas autoridades nem todas - foram assim retratadas.

Em Le Voyage de Gulliver a Lilliput et chez les geants (A viagem de Gulliver entre os liliputianos e os gigantes, 1902), aparecem mais alguns nobres barrigudos. Em Le palais des mille et une nuits (O palácio de mil e uma noites, 1905), há vários personagens representados por atores gordos ou com enchimento, atuando em posições de autoridade na narrativa - incluindo o rajah ou sultão. Vale destacar, também, a postura corporal - barriga para frente, com hiperlordose lombar, mas ombros baixos e para trás, peito estufado, com andar orgulhoso. Os barrigudos são representados como poderosos.

Em La légende de Rip Van Winckle (A lenda de Rip Van Winckle, 1905), um ator corpulento e barrigudo representa o Rei Jorge III, do Reino Unido, enquanto os demais papeis - dos membros da corte, soldados e demais cidadãos - foram todos representados por atores magros.

Em Le raid Paris Monte-Carlo em deux heures (A viagem entre Paris e Monte-Carlo em duas horas, 1905) aparece um personagem corpulento, com uma barriga sobressalente e uniforme de guarda, como supervisor da guarda. Este supervisor parte para cima dos guardas subalternos, dando-lhes barrigadas e derrubando-os. Ele se mostra irascível e dominante - aparentemente, por estes terem deixado uma pedestre passar sem pagar os impostos. Quando o carro, que é o protagonista, aproxima-se da entrada, o supervisor consegue desacelerá-lo e fazê-lo recuar usando sua barriga por duas vezes. Na terceira tentativa de entrada do automóvel, vários funcionários se aglomeram para tentar impedir, mas não conseguem, dependendo mais uma vez da ajuda do barrigudo, que demonstra ter sido representado como forte fisicamente. Numa quarta tentativa, o corpulento se distrai e o carro o explode, num efeito especial. 
No curta-metragem La cascade de feu (A cascata de fogo, 1904), o dono da casa é barrigudo, voluntarioso e irascível com seus dois empregados domésticos. Já em Tom Tight et Dum Dum (Tom Tight e Dum Dum, 1903), há um personagem gordo e um magro. O personagem barrigudo é representado pelo próprio Méliés, com enchimento na barriga e uma careca pontuda extravagante. A artificialidade torna a questão mais explícita, menos passível de discussões a respeito da intenção do realizador. Quando é utilizado um enchimento para parecer barrigudo ou corpulento, não há dúvidas de que esta característica corporal era desejável pelo diretor da obra. Primeiramente, o personagem barrigudo adentra a tela, seguido posteriormente do magro, que começa a dançar, chamando atenção para si. Nisso, o gordo se mostra incomodado, sentando-se num canto, arrumando a barriga e apoiando os braços sobre a pança, a observar. Em seguida, parte para cima do personagem magro e esmaga-o com um martelo gigante até enterrá-lo no chão. Deve-se destacar que o personagem se mostra bastante ativo e vivaz - sem qualquer sinal de inaptidão física. Ao fim do curta, o magro retorna e, novamente, é violentado pelo gordo, que desmembra o boneco que substituira o dançarino.

Em La bonne bergère et la mauvaise princesse (A pastora boa e a princesa má, 1908), a atriz que interpreta a princesa má é relativamente corpulenta, enquanto as demais atrizes são visivelmente menos volumosas. Ela é representada como voluntariosa, irascível e violenta, maltratando e agredindo várias pessoas. Mais uma vez, os membros da nobreza ou da elite são representados gordos. Como o curta tem um final feliz, a princesa má é aprisionada e lançada num fosso ao final.

O curta Le tonnerre de Jupiter (O trovão de Júpiter, 1903), apresenta enunciados mais claros - ainda que indiretamente tematizado - sobre a obesidade do personagem. O próprio Méliès atua no papel de Júpiter, usando um enchimento na barriga. Mitologicamente, Jupiter ou Zeus comumente era representado barrigudo, também devido à sua vinculação ao planeta, que é o maior do sistema solar. Não há, historicamente, nada de inovador nesse enunciado. Também da mitologia advém a informação de que esta divindade era o rei dos deuses e dono do raio. Por isso, o curta de Méliès brinca com a situação do raio de Júpiter estar estragado, exigindo os reparos de Hefesto, o artesão que consertava as armas dos deuses. Parte da irascibilidade que o rei dos deuses demonstrará advém do fato de seu raio ter se quebrado - e não diretamente por sua corpulência. As associações entre ideias, entretanto, agem mesmo que indiretamente sobre o inconsciente de quem as recepciona. Por isso, Júpiter ser considerado o rei dos deuses e ter sido representado como gordo, barrigudo, corpulento e irascível não deixa de ser significativo.

Num fragmento de um curta não identificado, datado de 1908, com 1 min. 32 s., novamente um magistrado é representado por um ator barrigudo. Igualmente, em Le tripot clandestine (A casa 
de apostas ilegais, 1905), o chefe da polícia, que fiscaliza um local suspeito (e culpado) de jogos de azar ilegais, também é barrigudo e corpulento. Além dos gestos de mando para com os policiais, a vestimenta - cartola e sobretudo - diferencia-o e posiciona-o líder da operação. Novamente, portanto, um barrigudo poderoso.

Por fim, no curta Voyage a travers l'impossible (Viagem através do impossível, 1904), além de trazer barrigudos em posições de autoridade, há quase uma hierarquização pelo tamanho da barriga, em que os que expressam maior poder são aqueles com as maiores circunferências abdominais. As indumentárias também ressaltam a riqueza, o status e o poder. Assim, o casal mais gordo se mostra com maior status. A esposa atua como voluntariosa e irascível. O corpo, entretanto, não é tematizado diretamente - nem mesmo através de gestos - agindo mais secundariamente como um símbolo de status, precedência e poder.

Por fim, tem-se, então, uma formação discursiva com um conjunto de enunciados cujo NC dos conteúdos das RS na filmografia de Méliès associam consistentemente a corpulência excessiva, a barriga grande ou a gordura corporal à certas condições socioeconômicas, de status e de poder. Em tempos de escassez alimentar, o senso comum premedita que se alguém é gordo é porque come bastante; e se come bastante é porque tem bastante dinheiro para comprar muita comida; logo, tem uma boa condição socioeconômica, proveniente de uma boa posição - seja ela proveniente de berço, como no caso dos nobres, ou de profissão, tal como juízes. Essa formação se diferencia daquela que se denominou do "burguês-gordo" (SANTOLIN e RIGO, 2019), por não se vincular à ideologia comunista.

\section{Peso-pesados}

Uma segunda formação discursiva identificada, composta por três filmes, é mais descritiva ao invés de sugerir correlações com outras variáveis - enunciando que os mais corpulentos são pesados. Em dois curtas, esse peso “excessivo" é representado como uma vantagem para lutas corporais, tanto por dificultar possíveis tentativas de levantar o lutador quanto por esmagar os adversários caso caiam em cima deles. Essa concepção ainda está presente em certas modalidades artes marciais, como no sumô e no judô.

O primeiro curta em que tais enunciados aparecem é em Nouvelles luttes extravagantes (Novas lutas extravagantes, 1900). No título em inglês, este filme recebeu o nome Fat and lean wrestling match - ou seja, a luta entre o gordo e o magro. Primeiramente, um homem corpulento e com cara brava adentra a tela pela esquerda, caminhando e se posicionando para o combate. $\mathrm{O}$ magro vem em seguida, caminhando pelo lado oposto, faz um cumprimento para os espectadores e 
se prepara para a luta. Ambos se cumprimentam e iniciam o confronto físico. O magro se movimenta, enquanto o gordo permanece parado. O magro parte em direção ao oponente e tenta levantá-lo do chão, mas só com muita dificuldade consegue, ao que o gordo expressa orgulho da superioridade defensiva que o peso the confere. O magro tenta novamente, mas nada consegue e depois se afasta, limpando o suor da testa pelo esforço cansativo e fracassado. Ele retoma o fôlego e parte para uma terceira tentativa de levantar o gordo, mas esse se desequilibra para frente, caindo em cima do magro, esmagando-o, sendo substituído - através de um corte - por uma cartolina desenhada, a qual o gordo manipula. Vendo seu sucesso na luta, o gordo fica de costas e comemora sua vitória, mas o magro retoma sua forma, levanta-se e dá um chute nas nádegas do gordo, que é arremessado, saindo da tela por cima. No entretempo até a queda do gordo sobre a cabeça do magro, este comemora a vitória, mostrando seus braços. Após a queda, o gordo permanece sentado e, depois, o magro o deita e pula em cima de sua barriga, ao que o ator é substituído por um boneco e um efeito de fumaça é criado para dar a impressão de estouro. O magro comemora e se gaba, saindo da tela caminhando. Enquanto isso, as partes do boneco que representavam o gordo se rejuntam até serem substituídas pelo ator, que se levanta e gesticula em direção a seu oponente que saiu de cena.

Em Le conseil du pipelet ou un tour à la foire (O conselho de pipelet, ou, Um tour na feira, 1908), novamente uma luta em que uma personagem gorda enfrenta um magro. Mais uma vez, enuncia-se que o corpulento é pesado - quem o enfrenta não consegue tirá-lo do chão e quando cai em cima esmaga.

Em Le chapeau a surprise (O chapéu tem uma surpresa, 1901), Méliés aparece no papel de mágico, retirando objetos e pessoas de dentro de sua cartola. Além de vários objetos, ele retira três moças da cartola. No momento seguinte, entretanto, quando observa dentro da cartola gigante, faz gestos no ar com as mãos, sinalizando uma grande barriga, além de inflar as bochechas com ar, complementando os símbolos para significar para o espectador que se trata de um sujeito corpulento, barrigudo e pesado. Após isso, ele gesticula negativamente, deslocando-se para frente da cartola gigante e - ao invés de puxar o sujeito, como fez com as moças - ele vira a cartola para que seu conteúdo caia. $\mathrm{O}$ ator está trajado nobremente, tal como um rei, e saúda as damas à mesa, sentando-se em seguida. $\mathrm{O}$ enunciado neste curta postula, unicamente, que corpulentos-barrigudos são pesados - nada acrescentando mais a respeito.

Ainda que mais descritiva, nesta formação discursiva se percebe mais claramente - mesmo que pontualmente, numa única variável - uma tentativa de pensar uma condição corporal que fora problematizada - ou seja, de ponderar o que poderia haver de bom ou de ruim na corpulência "excessiva". No caso de Méliès, fica-se com a impressão que ele sugere mais pontos positivos do 
que negativos. Os principais enunciados são: a) aqueles que têm um corpo grande e volumoso têm uma massa corporal maior; e, b) esta característica pode ser uma vantagem nos confrontos físicos.

\section{Encorpados}

Esta formação discursiva se caracterizou por enunciar somente que um corpulento é equivalente a três ou quatro pessoas - sem expressar necessariamente um juízo de valor a respeito disso. De fato, dizer que alguém vale por várias pessoas pode significar algo desejável ou não. Essa equivalência, entretanto, é mais de ordem física mesmo - relacionada ao tamanho do corpo e à circunferência da barriga. Identificou-se dois curtas em que um enunciado desse tipo ocorreu. Num deles, houve uma expressão de desvalorização, enquanto no outro não.

Em Tom Whisky ou L'illusionniste toque (Tom Whisky, ou, O toque ilusionista, 1900), três mulheres magras são transformadas em uma mulher gorda, que depois é dividida novamente em três mulheres magras. Após o "truque", o mágico - representado pelo próprio Méliés - faz gestos, apontando para a corpulenta, em relação às bochechas e à barriga, batendo em seguida nas coxas, como se, por si só, a corpulência dela fosse hilário, motivo de riso. O enunciado neste caso sugere que uma mulher corpulenta, gorda, seria como três magras e, posteriormente, que esta corpulência “excessiva" seria motivo de riso e ridicularização.

Também em L'omnibus des toques ou blancs et noirs (O ônibus dos toques, ou, Brancos e pretos, 1901), apresenta-se essa ideia de incorporação-encorpação - três homens sobem, sequencialmente, nas costas de um quarto homem, incorporando-se neste, que se torna barrigudo, com um grande enchimento na barriga. Após isto, ele caminha em círculo com certa dificuldade. Nenhuma valoração, entretanto, a respeito desta corpulência é expressa.

Assim, através dessas "incorporações" - numa espécie de fagocitose corporal, produzidas com efeitos especiais - Méliès fantasia corpulentos "encorpados", sugerindo sutilmente uma desvalorização dessa corpulência excessiva.

\section{(In) capacidades físicas}

Em quatro curtas foram identificados enunciados referentes à questão da mobilidade e da aptidão cardiorrespiratória - sem, entretanto, haver uma patologização da condição.

O curta Voyage a travers l'impossible (Viagem através do impossível, 1904), uma funcionária que segue a comitiva de viajantes e ocupa a posição de autoridade mais baixa é também a mais magra e ativa fisicamente. Em certo momento, ressalta-se a dificuldade de mobilidade do 
casal corpulento, sendo necessário inclusive ajudar a esposa a subir no trem. Deve-se destacar, porém, que a mobilidade não é representada como algo valorizado nos curtas de Méliès - assim como na época. Nos curtas, comumente, figuras malignas, como o diabo e demônios, são representadas realizando acrobacias - cambalhotas, saltos, danças, piruetas, contorções, dentre outros. A mobilidade - tanto a corporal quanto a socioeconômica - simboliza algo indesejável, a própria maldade numa sociedade conservadora, que preza pela imobilidade, fazendo-o tanto no âmbito socioeconômico quanto corporal. Vale destacar que Méliès era herdeiro de uma fábrica de botas e, portanto, pertencia à "elite" parisiense, produzindo entretenimento, provavelmente, para as "categorias" menos favorecidas. Do ponto de vista ideológico, pode-se considerar suas obras conservadoras e não contestadoras. Assim, as personagens representantes do bem só fazem gestos e movimentos mínimos - simbolizando tanto a imobilidade corporal quanto a socioeconômica.

As mobilidades corporal e socioeconômica só serão valorizadas ao longo do Século XX. Nos Séculos XVIII e XIX, os circos e os artistas circenses inspiravam desconfiança, tanto por vagarem entre as cidades (mobilidade geográfica) quanto por realizarem acrobacias consideradas movimentos inúteis - como se pode ler em Soares (1998). O movimento ginástico europeu, atrelado a patriotismos, os exércitos nacionais e as guerras nacionalistas começarão a inverter esse sistema de valores ao longo do Século XIX (MARINHO, 1980). Nos primórdios do Cinema, entretanto, as representações que Méliès apresenta ainda remetem ao sistema de valores antigo - mesmo tendo sido no começo do Século XX.

Em Le royaume de fees (O reino das fadas, 1903), um personagem corpulento e barrigudo chama atenção por se mostrar atrapalhado ao vestir a armadura, necessitando inclusive de ajuda para tal. Nenhum outro soldado precisou de auxílio. Na hora de subir a escada, seu companheiro empurra-o para subir, enquanto ele abana os braços desajeitadamente. Em outras cenas, o personagem mostra-se igualmente atrapalhado.

Em Les patineurs (Os patinadores, 1908), um personagem caricaturiza uma pessoa extremamente corpulenta, com uma vestimenta enorme, repleta de ar. Ele é posicionado num pequeno palco, atrás daqueles que eram para ser os protagonistas do curta - os patinadores - mas acaba atraindo bastante atenção para si. No plano seguinte, ao sair do restaurante, ele e seus companheiros são abordados por vendedores de patins. O corpulento age generosamente, comprando para si e para os demais, presenteando-os. No plano seguinte, o grupo aparece numa sala de jantar, calçando os patins. Em seguida, começam a patinar no salão - inclusive o corpulento, que já aparece com os patins calçados. Ele cai num determinado instante e aparenta certa dificuldade para levantar, mas, ao final, consegue fazê-lo sozinho. Outros também caem e não se pode interpretar em sua queda sinal de imperícia ou incapacidade. Ambos patinadores derrubam e 
reviram todos os objetos da sala de jantar, sendo levados para o presídio pela baderna - com exceção do corpulento, que não é mais retratado. Neste curta, diferentemente dos anteriores analisados, enuncia-se que a mobilidade dos corpulentos é "normal”, não havendo limitações. A mobilidade apresentada não é de tal nível como daqueles que representam figuras diabólicas e malignas, mas também não é mais baixa que a dos demais personagens magros.

Em Le tonnerre de Jupiter (O trovão de Júpiter, 1903), Hermes ou Mercúrio intermedia a ordem de Júpiter para Hefesto. Mercúrio é representado de modo clássico - correndo, ligeiro, segurando um caduceu. Tais associações vieram de analogias astronômicas, já que este planeta descreve a órbita translacional mais rápida. Júpiter tenta acompanhar o ritmo de Mercúrio, realizando uma corrida estática, mas não consegue, demonstrando linguagem corporal de cansaço e exaustão, levando as mãos aos joelhos ofegantemente. O enunciado neste caso é que gordos, corpulentos tem pouco fôlego ou baixa capacidade cardiorrespiratória.

Em suma, nesta formação discursiva, em que se pauta as capacidades físicas da condição corporal em foco, há tanto enunciados que problematizam a condição negativamente quanto enunciados que proferem discursos opostos, caracterizando-se por uma inconsistência no NC dos conteúdos das RS analisadas para este quesito. No primeiro caso, os enunciados seriam que a corpulência excessiva dificulta a mobilidade e que corpulentos são inaptos cardiorrespiratoriamente; enquanto no segundo caso, a mobilidade e a aptidão cardiorrespiratória dos corpulentos é normal, equivalente à dos não corpulentos.

\section{Embompoint excessive}

Numa subsérie de três curtas, identificou-se uma formação discursiva que trata da questão da beleza e da atratividade, especificamente, de mulheres corpulentas. Apesar de situado no Século $\mathrm{XX}$, trata-se ainda do embonpoint, "em-bom-ponto", conceito francês remanescente do Século XVIII, que atribuía beleza às mulheres com certo grau de corpulência, tal como descrito em Santolin (2012).

Em Le mariage de Victoire (O casamento de Vitória, 1907), uma das protagonistas é uma empregada doméstica gordinha, que permite, inautorizadamente, que um soldado pretendente esteja na cozinha. Ele galanteia e ela cede às investidas, sentando em seu colo. Aqui enuncia-se, implicitamente, que a corpulência "excessiva" não torna a mulher indesejável ou inabilitada amorosamente - como posteriormente na história das representações da obesidade será enunciado. Após isso, é mostrado os patrões, na sala de jantar ao lado, tentando sem sucesso requisitar os serviços de sua funcionária. Ao dirigirem-se à cozinha para ver o que havia acontecido, a cozinheira 
esconde o namoradinho numa caixa e finge ter um mal-estar para justificar o não atendimento. Os donos decidem, então, realizar a refeição na mesa da cozinha. O intruso, porém, tenta fugir da situação pela chaminé, no que é perseguido pela polícia e pelos donos da casa. Após despistá-los, retorna à cozinha, onde resgata a cozinheira e fogem da casa. A história termina com um final feliz para o casal, mostrando os amantes num close, em primeiro plano, aos beijinhos.

Em Le raid Paris Monte-Carlo em deux heures (A viagem entre Paris e Monte-Carlo em duas horas, 1905) uma personagem corpulenta atuando como feirante é recepcionada por guardas que lhe deveriam cobrar uma taxa na entrada. Estes, entretanto, deixam-na passar sem pagar, e, após ela se virar, fazem gestos com as mãos em referência à seu corpo, num sentido, aparentemente, elogioso e não pejorativo. Aqui pode-se perceber representado o estereótipo de beleza ainda invertido em relação ao que se tem contemporaneamente. Tratava-se, assim como no curta anterior, do embonpoint.

Em Pour l'etóile S.V.P (Para a estrela S.V.P., 1908), um homem visa entregar um buquê de flores para a celebridade S.V.P., mas acaba entregando para a "mulher errada". A personagem é representada por uma mulher corpulenta e a linguagem corporal dos demais personagens demonstra que ela é considerada feia e indesejável, motivo de estigmatização, inclusive, para o galanteador. Os personagens apontam na direção dela e riem, enquanto ela chora, ao ser rejeitada pelo homem. Ainda que o critério avaliativo fosse visual, o embonpoint também podia ser considerado excessivo.

Tem-se, enfim, nesta formação discursiva enunciados que realizam juízos de valor positivo a respeito da beleza, da atratividade e do sex appeal de personagens com certa corpulência. Deve-se sublinhar o fato de que foi exclusivamente em relação às mulheres, não tendo sido encontrado enunciados desse tipo para os diversos personagens corpulentos, barrigudos ou gordos que aparecem nas centenas de filmes.

\section{Guloso}

Um único filme retratou a corpulência associada à excesso alimentar - à gula. Em Entre Calais et Douvres (Entre Calais e Dover, 1897), um navio está navegando, com muita oscilação, como se prestes a naufragar. Vários personagens podem ser vistos, mas dois se destacam - um que caminha com um livro aberto, a ler, e outro sentado a uma mesa, a comer. Este foi trajado com enchimentos em suas roupas, para aparentar corpulência e barriga grande; enquanto aquele foi representado magro.

O enunciado identificado remete à noção de gula - já que mesmo prestes a naufragar, o corpulento está a comer e beber. Ou seja, nem assim um barrigudo para de comer e beber. De certo 
modo, pode-se dizer que, ao associar a característica corporal e comportamental, a mensagem ganha conotações etiológicas, sugerindo, implicitamente, que a causa da corpulência é a gula e excessos alimentares.

\section{CONCLUSÕES}

A pesquisa permitiu identificar seis formações discursivas distintas, com conteúdos enunciativos que associam a condição à questão do status social, da saúde, da beleza, das capacidades físicas e do comportamento. Em algumas formações, não houve uma consistência enunciativa, ocorrendo, muitas vezes, conteúdos opostos.

Ao analisar a historicidade das RS na filmografia de Méliès, pode-se perceber que sua obra parte de concepções típicas do período pré inversão valorativa - ainda populares na virada do século - para uma concepção desvalorizada da gordura corporal e da corpulência "excessivas", tal como na contemporaneidade. Assim, de enunciados que positivam a condição no começo de seus filmes, ainda no século XIX, tem-se ao fim de sua carreira, já quase na virada para a década de 10 no século XX, enunciados que negativam a condição. De bela, forte, com boa posição socioeconômica - apesar de um pouco gulosos e irascíveis - à doentes, com dificuldade de mobilidade, com baixa aptidão cardiorrespiratória. Outrora, mesmo os "defeitos" eram minorados e positivados, tal como o peso corporal "excessivo" nas lutas.

Nos curtas, também por não haver falas, tem-se, no máximo, referências à aparência ou ao peso, sendo mais adequado falar sobre a circunferência abdominal, o tamanho ou a massa corporal. Apesar disso, deve-se considerar tais achados como pertencentes à história da obesidade, dado o fato de que no princípio foram tais variáveis que foram problematizadas, sendo, portanto, precursoras da patologização.

Faz-se necessário destacar, novamente, os silenciamentos, tal como sugere Foucault (2008), já que eles também enunciam. Não houve, por exemplo, enunciados que pautassem a questão da beleza da corpulência "excessiva" masculina, o que pode ser relevante para estudos feministas. Outro exemplo é em relação à formação discursiva de força física, não houve enunciados em que esta capacidade falhasse, tal como será no expressionismo alemão em A última gargalhada (1924), de F. W. Murnau.

Mais importante do que os pormenores analíticos específicos da série analisada é o fato do material indicar - indiretamente, mas empiricamente, dado as RS existentes - que o Cinema pode ter sido uma importante ferramenta na difusão dos novos valores associados à corpulência e à 
gordura corporal excessiva nos processos históricos de inversão valorativa e de patologização da obesidade.

Assim, por fim, reitera-se a necessidade de outras pesquisas deste tipo, sobre este e outros períodos, compondo mais séries para a produção de uma história serial mais ampla, que permita compreender melhor o presente através do passado que o constituiu.

\section{REFERÊNCIAS}

A ÙlTIMA GARGALHADA. Direção de F. W. Murnau. Preto e branco, 77 min. Alemanha: Universum Film, 1924. Disponível em: https://www.youtube.com/watch?v=N9dBbOlX4Zg . Acesso em 17 de Janeiro de 2019.

BAECQUE, Antoine. Le discours anti-noble (1787-1792) aux origines d'un slogan: "Le peuple contre les gros". Revue d'Histoire Moderne et Contemporaine. Tomo XXXVI. 1989, p.3-28.

BAHIANA, Ana M. Como ver um filme. Rio de Janeiro: Nova Fronteira, 2012.

BARROS, José A. História serial, História quantitativa e História demográfica: uma breve reflexão crítica.

Revista de C. Humanas, Vol. 11, No 1, p. 163-172, jan. /jun. 2011.

BARROS, José A. A História serial e História quantitativa no movimento dos Annales. Hist. R., Goiânia, v. 17, n. 1, p. 203-222, jan. /jun. 2012.

BARROS, José A.O projeto de pesquisa em História: da escola do tema ao quadro teórico. $9^{\text {a }}$ ed. Rio de Janeiro: Vozes, 2013.

BRASIL. Lei n ${ }^{\circ} 9.610$, de 19 de Fevereiro de 1998. Altera, atualiza e consolida a legislação sobre direitos autorais e dá outras providências. Disponível em: http://www.planalto.gov.br/CCIVIL_03/LEIS/L9610.HTM . Acesso em 25 de Agosto de 2018.

FOUCAULT, Michel. A arqueologia do saber. $7^{\mathrm{a}}$ ed. Rio de Janeiro: Forense Universitária, 2008.

FOUCAULT, Michel. A coragem da verdade. São Paulo: WMF, 2011.

GADAMER, Hans-Georg. Verdade e método: traços fundamentais de uma hermenêutica filosófica. $15^{\text {a }}$ ed. Rio de Janeiro: Vozes, 2014.

GEORGES MÉLIÈS: the first wizard of Cinema (1896-1913). Direção de Georges Franju. Coleção. Lobster films. 6 DVDs. 896 min, França, 2010.

GUIMARÃES, Pedro M. Corpo e citação. In: SAURA, S. C.; ZIMMERMANN, A. C. (org.) Cinema e corpo. Cap.1. São Paulo: Laços, 2016, p.21-32.

INTERNET MOVIE DATABASE (IMDb). Disponível em:https://www.imdb.com/name/nm0617588/?ref =nv sr 1Acesso em 21 de Setembro de 2018.

JULLIER, Laurent; MARIE, Magda; MARIE, Michel. Lendo as imagens do cinema. São Paulo: SENAC São Paulo, 2012.

LA MAGIE MÉLIÈS. Direção de Jacques Mény. Documentário, 2h06min, França, 1997. Disponível em: https://www.youtube.com/watch?v=1ThCusVQ4Zw Acesso em 21 de Setembro de 2018. 
MARINHO, Inezil P. História geral da Educação Física. São Paulo: Cia Brasil, 1980.

MOSCOVICI, Serge. Representações sociais. $7^{\text {a }}$ ed. São Paulo: Vozes, 2010.

PATRIOTA, Lucia M. Teoria das Representações Sociais: Contribuições para a apreensão da realidade. Disponível em: http://www.uel.br/revistas/ssrevista/c-v10n1 lucia.htm\#: :text=Quanto $\% 20 \% \mathrm{C} 3 \% \mathrm{~A} 0 \mathrm{~s} \% 20$ fun $\% \mathrm{C} 3 \% \mathrm{~A} 7 \% \mathrm{C}$ 3\%B5es $\% 2 \mathrm{C} \% 20$ as $\% 20$ representa $\% \mathrm{C} 3 \% \mathrm{~A} 7 \% \mathrm{C} 3 \% \mathrm{~B} 5$ es, et $\% 20$ son $\% 20$ public $\% 20(1961)$.\&text $=(\mathrm{Abric} \% 2 \mathrm{C}$ \%201998\%3B\%20Moscovici\%2C,1978\%3B\%20Jodelet\%2C\%201986). Acesso em 18 de Setembro de 2020.

POULAIN, Jean-Pierre. Sociologia da obesidade. São Paulo: SENAC São Paulo, 2014.

QUELLIER, Florent. Gula: história de um pecado capital. São Paulo: SENAC, 2011.

SABADIN, Celso. Vocês ainda não ouviram nada: a barulhenta história do cinema mudo. $2^{\mathrm{a}}$ ed. São Paulo: Lemos, 2000.

SANTOLIN, Cezar B. O nascimento da obesidade: um estudo genealógico do discurso patologizante.

Dissertação de mestrado. Pelotas, RS. Universidade Federal de Pelotas (UFPel), 2012.

SANTOLIN, Cezar B.; RIGO, Luiz C. A obesidade e a problematização da corpulência na Idade Média. FIEP BULLETIN - Volume 82 - Special Edition - ARTICLE I - 2012.

SANTOLIN, Cezar B.; RIGO, Luiz C. O nascimento do discurso patologizante da obesidade. Movimento. Porto Alegre, v.21, n.1, p.81-94, jan./mar. de 2015.

SANTOLIN, Cezar B.; RIGO, Luiz C. Por que o termo "gordo" se tornou politicamente incorreto no Brasil? Anais do VI Congresso Sulbrasileiro de Ciências do Esporte. Set./2012. Disponível em:

http://congressos.cbce.org.br/index.php/conbrace2011/2011/paper/view/3079Acesso em 15 de Outubro de 2020.

SANTOLIN, Cezar B.; RIGO, Luiz C. Representações da obesidade no cinema: o "burguês gordo" em A greve (1925) de Eisenstein. Movimento. V. 25, e25076, 2019.

SOARES, Carmen. L. Imagens da educação no corpo: estudo a partir da ginástica francesa do Século XIX. Campinas: Autores associados, 1998.

STRUNA, Nancy. L. Pesquisa histórica em atividade física. In: THOMAS, Jerry. R.; NELSON, Jack. K.; SILVERMAN, Stephen. J. Métodos de pesquisa em atividade física. $5^{\mathrm{a}}$ ed. Cap. 12. Porto Alegre: Artmed, 2007, p. 189-201.

VIGARELLO, Georges. As metamorfoses do gordo. Rio de Janeiro: Vozes, 2012.

\section{NOTAS DE AUTOR}

AGRADECIMENTOS - Não se aplica.

CONTRIBUIÇÃO DE AUTORIA - Não se aplica.

FINANCIAMENTO - Não se aplica. 
CONSENTIMENTO DE USO DE IMAGEM - Não se aplica.

APROVAÇÃO DE COMITÊ DE ÉTICA EM PESQUISA - Não se aplica.

\section{CONFLITO DE INTERESSES}

O autor declara não ter havido conflito de interesses na produção desta pesquisa.

\section{LICENÇA DE USO}

Os autores cedem à Motrivivência - ISSN 2175-8042 os direitos exclusivos de primeira publicação, com o trabalho simultaneamente licenciado sob a Licença Creative Commons Attribution Non-Comercial ShareAlike (CC BY-NC SA) 4.0 International. Esta licença permite que terceiros remixem, adaptem e criem a partir do trabalho publicado, desde que para fins não comerciais, atribuindo o devido crédito de autoria e publicação inicial neste periódico desde que adotem a mesma licença, compartilhar igual. Os autores têm autorização para assumir contratos adicionais separadamente, para distribuição não exclusiva da versão do trabalho publicada neste periódico (ex.: publicar em repositório institucional, em site pessoal, publicar uma tradução, ou como capítulo de livro), com reconhecimento de autoria e publicação inicial neste periódico, desde que para fins não comerciais e compartilhar com a mesma licença.

\section{PUBLISHER}

Universidade Federal de Santa Catarina. Programa de Pós-Graduação em Educação Física. LaboMídia - Laboratório e Observatório da Mídia Esportiva. Publicado no Portal de Periódicos UFSC. As ideias expressadas neste artigo são de responsabilidade de seus autores, não representando, necessariamente, a opinião dos editores ou da universidade.

\section{EDITORES}

Mauricio Roberto da Silva, Giovani De Lorenzi Pires, Rogério Santos Pereira.

EDITOR DE SEÇÃO

Juliano Silveira

REVISÃO DO MANUSCRITO E METADADOS

João Caetano Prates Rocha; Keli Barreto.

\section{HISTÓRICO}

Recebido em: 16 de outubro de 2020.

Aprovado em: 25 de novembro de 2020. 